\title{
Erosion Corrosion and Protection of Recycle System with Seawater
}

\author{
Jin $\mathrm{XUE}^{1,}$,, Kaijie XUE ${ }^{2,}$ b and Jianshu LU ${ }^{1, c}$ \\ ${ }^{1}$ Zhejiang University of Technology Hangzhou 310014 P.R. China \\ 2 Toronto University George St Toronto Ontario M5S3G3 Canada \\ ${ }^{a}$ zcpsic@zjut.edu.cn'1 ${ }^{b}$ shenjm_hw@163.com, ${ }^{c}$ jianshul@zjut.edu.cn
}

\begin{abstract}
In order to investigate the corrosion of recycle system with seawater in rights of power plant, the erosion behavior and mechanism of erosion corrosion in this system constructed with several corrosionresistance alloys have been studied and tested in the condition of high speed fluid with a sand particles. Both special protection technologies and results, one designed by high temperature epoxy resin powder coating and another of the associating method of anode protection together with such same coating, have been discussed as well in this case.
\end{abstract}

\section{Introduction}

A serious destruction and corrosion had been appeared for recycle system used in the application with the medium of sea-water in some of nuclear power plant within 5 years usage. Due to the fact of corrosion and pit leak formed, the seawater leaked out and ejected as a column from the pit leaks of the system.

With the further inspection for this system or any others used in the same power plant, it was discovered that all of inner surface of pipes have been rusted and covered with a brow -yellow rusty layer, which there were a lot of corrosion knobble in, with a hard shell and full of corrosive debris.

The matrix metal under that layer has corroded seriously, and a numerous of in-regular and ulcerous corrosion pits were exhibited, including some of much bigger pits or even cavitations caused by erosion. In the same time, it was discovered that there were several bigger cavitations on the thermal effective area of $3 \mathrm{~cm}$ welding junction and the ditches as fluidity on the inner surface of failure valve, due to the fact of acceleration effect of corrosion in weld zone of screwed pipe.

\footnotetext{
* Corresponding author:zcpsic@zjut.edu.cn
} 


\section{Experiment and Result}

\subsection{Metallographic and Constitution Analysis for Pipe Corroded}

The materials used for recycle system should be considered as 10CrMoAl, a kind of low alloy steel with the properties of marine corrosion resistance in terms of initial design. However, with the analysis of AES and metallographic, it was the plain carbon steel used for this application.

With further inspection of metallographic Fig 1), it was discovered that crystal grain of that pipe material was bigger than normal and composted by ferrite and pearlite in constitution typically. The pearlite existed in constitution of welding zone was less than that of in matrix (Fig 2), and it was distributed along with the crystal boundaries of ferrite. And there was not any corrosion cracking or SCC existed on the subsurface of welding zone.

Widmanstatten structure is a kind of unstable needlelike ferrite constitution appeared in the bigger grains of pearlite (Fig 3), and it will accelerate the corrosion process. It was discovered that this structure was seriously appeared in the constitution of thermal effective area of welding junction.

\subsection{Analysis of Surface Corroded with SEM}

With SEM analysis of topography of inner surface of pipe, It was discovered that there were a lot of accumulative corrosives on the surface. As such corrosives to be cleaned out by basic solvent with Potassium Hypermanganate, there was not any micro- crack, but only some of big concave pits corroded on the surface (Fig 4).

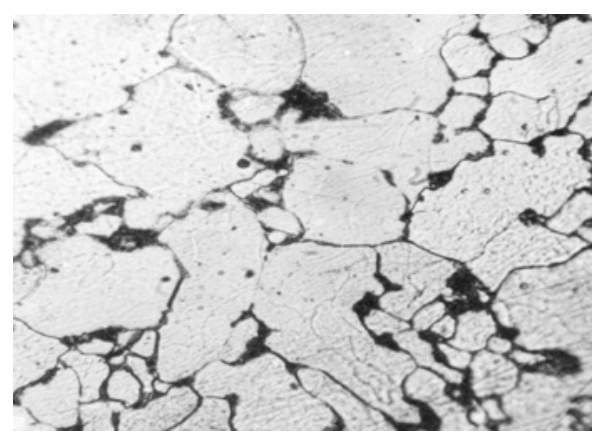

Fig 1 The metallographic constitution of pipe $\times 440$

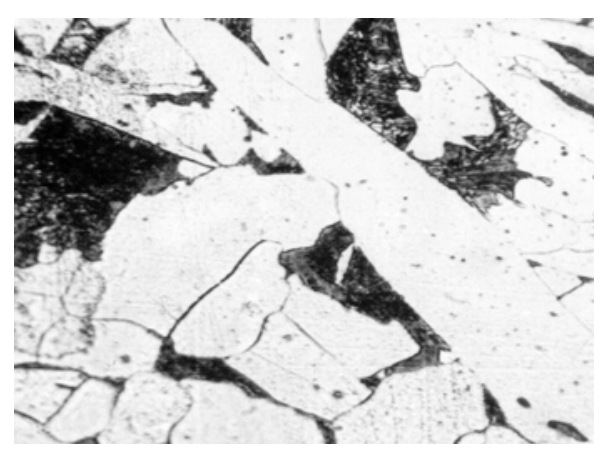

Fig 2 The metallographic constitution near the welding zone $\times 440$ 


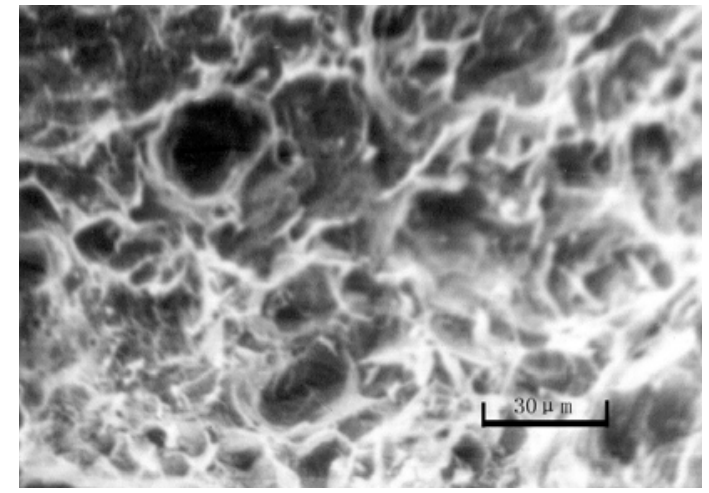

Fig 3 The metallographic constitution of thermal effective area $\times 440$

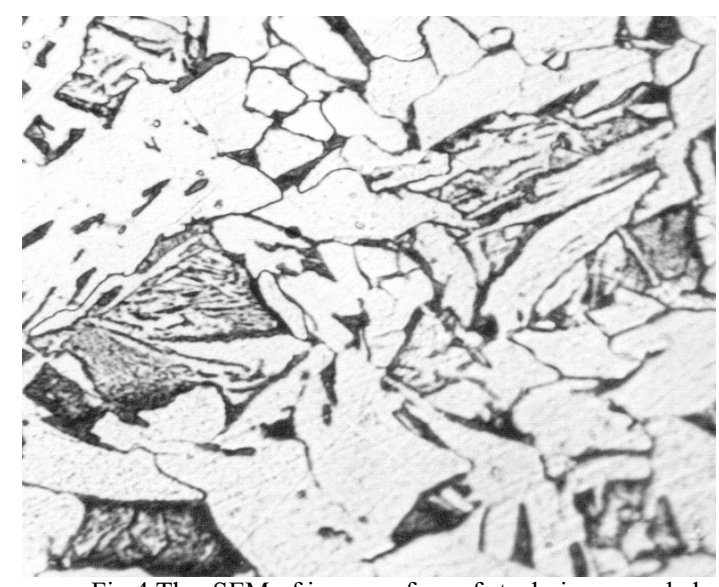

Fig 4 The SEM of inner surface of steel pipe corroded

\subsection{Investigation of Corrosion Knobble with X-ray Diffraction}

With X-ray diffraction, the composition and crystalline structure of corrosive powder taken from the knobble with a hard shell on the inner surface of pipe has been analyzed, and the result is as follows:

$$
\begin{array}{ll}
\text { Main composition or phase } & \mathrm{Fe}(\mathrm{OH})_{3}, \alpha-\mathrm{FeO}(\mathrm{OH}) \\
\text { Rest composition or phase } & \xi-\mathrm{Fe}_{2} \mathrm{O}_{3}, \mathrm{Fe}_{2} \mathrm{O}_{3} \bullet \mathrm{H}_{2} \mathrm{O} \text { and } \\
& \text { Non-crystal Ca, Si compound }
\end{array}
$$

All of corrosives to be analyzed above were $\mathrm{Fe}^{+++}$compound which was included with different crystallization phases or crystal water, and there was not any $\mathrm{Fe}^{++}$compounds, such as $\mathrm{FeO}$ or $\mathrm{Fe}_{3} \mathrm{O}_{4}$ existed. So it was explained that there was a great quantity of oxygen in high fluidity seawater, and in other hand, the non-crystal $\mathrm{Ca}, \mathrm{Si}$ compound appeared in corrosive was considered to come from the seawater or sea sand 


\subsection{Erosion Corrosion Test with Sea-water}

Total nine materials including plain carbon steel, HSLA, duplex stainless steel, Ti alloy, PTFE, PVC. Ni-P alloy coating and two of epoxy coating have been tested under the erosion corrosion test with seawater taken from the recycle system of power plant. The corrosion rate of above materials have been measured in the condition of $\mathrm{pH} 6,8$, salt content $12.5 \%$, sand $3-4 \mathrm{Kg} / \mathrm{m}^{3}$, fluid rate $6.18 \mathrm{~m} / \mathrm{s}$, and duration $48 \mathrm{hr}$

There were high corrosion rate for both plain carbon steel and HSLA. They were little difference at value of $2.10 \mathrm{~mm} / \mathrm{a}$ and $2.07 \mathrm{~mm} / \mathrm{a}$ respectively and in this test. HSLA would not reveal its excellence at marine protection.

However, it had a good effect of $99 \%$ protection and very low corrosion rate for plain carbon steel associated with the protection of ternary $\mathrm{Zn}$ alloy as sacrificial corrosion. It was shown that the corrosion rate of A3 steel sample was only $1.8 \times 10^{-2} \mathrm{~mm} / \mathrm{a}$ under the condition of $6.18 \mathrm{~m} / \mathrm{s}$ fluid rate, $627 \mathrm{hr}$ test duration and ternary $\mathrm{Zn}$ alloy protection as well. In the other hand, the duplex stainless steel, Ti-alloy and Ni-P alloy, all of them revealed their excellence at marine protection in the test. It was in special for Ti-alloy and the corrosion rate measured was zero in this case. The epoxy pitch coating is not available to be used, as it was the worst one in comparing with other materials, including PTFE, PVC, SEBF (high temperature epoxy coating)

Table 1 The Erosion Corrosion Rate For Different Materials In Sea-Water

\begin{tabular}{|l|c|l|l|l|l|c|}
\hline \multicolumn{1}{|c|}{ Material } & $\begin{array}{c}\text { Duplex } \\
\text { stainless steel }\end{array}$ & $\begin{array}{l}\text { Ti } \\
\text { allo } \\
\text { y }\end{array}$ & $\begin{array}{l}\text { Ni-P } \\
\text { alloy }\end{array}$ & PTFE & PVC & $\begin{array}{c}\text { Epoxy } \\
\text { pitch } \\
\text { coating }\end{array}$ \\
\hline $\begin{array}{l}\text { Corrosion } \\
\text { Rate(mm/a) }\end{array}$ & $9.2 \times 10^{-3}$ & 0 & $\begin{array}{l}6.3 \times 10 \\
-3\end{array}$ & $\begin{array}{c}4.5 \times 10 \\
-2\end{array}$ & $\begin{array}{c}5.6 \times 10 \\
-2\end{array}$ & $\begin{array}{c}4.9 \times 10 \\
-1\end{array}$ \\
\hline
\end{tabular}

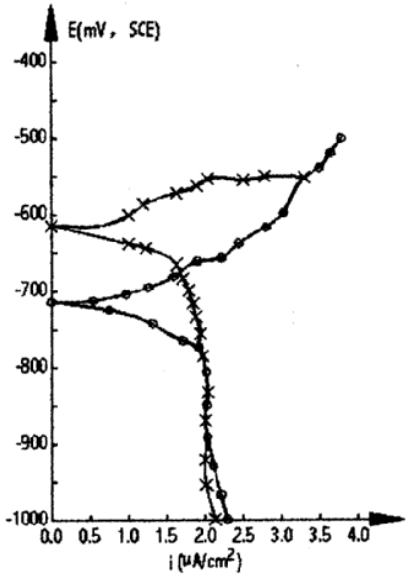

Fig 5 The polarization curves of both materials in static seawater $\bullet \mathrm{A} 3, \times 10 \mathrm{CrMoAl})$

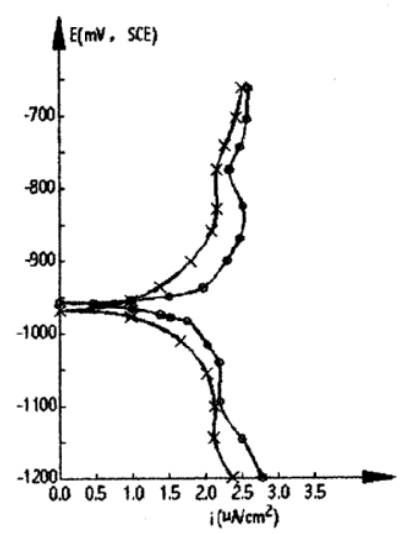

Fig 6 The polarization curves of both materials in fluidity seawater $\bullet \mathrm{A} 3, \times 10 \mathrm{CrMoAl})$

\subsection{Electrochemistry Measuring}

In order to investigate the corrosion characters of different materials under the condition of seawater, the polarization curves of plain carbon steel (A3 steel ) and HSLA (10CrMoAl) 
have been measured and studied in both of static and fluidity seawater as shown in following Fig5 and Fig6

It is viewed that the corrosion resistance of HSLA (10CrMoAl) was a little bit batter than that of plain carbon steel (A3 steel ) in this system, special in test of static seawater, due to the fact that the electrochemistry behavior for this system was a kind of oxygen adsorption reaction in cathode process with a diffusion control evidently. The limited current density in diffusion process would increase with the increasing of fluid rate of seawater.

\section{Discussion and Conclusion}

It has been proved that there was not any interganular corrosion, selective corrosion, SCC or any other localized corrosion happened on the corrosive surface in this case with the analysis of SEM and Metallographic, as the erosion corrosion appeared on the inner surface of pipe was result of high fluid of sea-water containing mud and sand absolutely. In this way, the erosion would accelerate the process of corrosion, and in turn reacted on it with the rough surface caused by corrosion aggravated. Some of cavitations of pipes would be caused by effect of inhomogeneous corrosion under the rusty or unstable constitution in thermal effective area of welding junction.

It has obtained from the erosion corrosion test with sea-water that both plain carbon steel (A3) and low alloy steel (10CrMoAl) are not so good in properties of erosion corrosion resistance. The corrosion rate of $\mathrm{A} 3$ steel is less than that of $10 \mathrm{CrMoAl}$ in test initially and at final result, the former is more than latter in contrariness. Anyway, both of materials talked above are not suitable for usage in the application of recycle system for sea-water.

It has approved that plain carbon steel associated with anodic protection of ternary $\mathrm{Zn}$ alloy posses a good erosion corrosion resistance in marine environment as well as the SEBF coating, which has a distinct advantage of chemical stability, wear resistance, impact strength, high adhesion strength, smooth appearance and has let to optimal suitability for application of recycle system. Although the PTFE coating has a superior property in erosion resistance, as same as the coating of SEBF, it is not much available to be used in this case due to the fact of restriction of higher expense, complex technology and low adhesion strength with matrix. Duplex stainless steel and Ti-alloy exhibit excellent erosion corrosion resistance in marine, and they are recommended as slender pipe materials or some key parts used in special.

In terms of test and investigation in lab, both of high temperature epoxy powder coating and associating method of such coating with anode protection have been recommended as a kind of protection technology and treatment in the application of recycle system for seawater. For slender pipe or some facility in special, it is better to be selected for the materials of Ti-alloy pipe or tar epoxy-PA resin or pure epoxy coating instead. 


\section{References}

1. Madsen B W. Measurement of erosion-corrosion synergism with a slurry wear test apparatus[J]. Wear, 1988, 123(2):127-142

2. J. Postlethwaite The control of erosion-corrosion in slurry pipelines;Materials Performance, 1987.v. 26, pp. 41-45,

3. Liu Huifang, Gao Jin, LI Xiaogang, Wu Junsheng; Erosion-corrosion characteristic of high velocity arc sprayed $\mathrm{FeCrAl}$ and $3 \mathrm{Cr} 13$ coating [J]. Journal of Chinese Society for Corrosion and Protection;2008-04

4. Zhang Ju-chuan, Duan Long-chen, Xie Bei-ping; Erosion-corrosion of co-base matrix material of bits under the impingement of salt water with sand[J].Geological Science and Technology Information;2010(3) 139-142

5. Ding Yi-gang, Wang Hui-long, Guo Xingpeng; Erosion-corrosion of metals and alloys in liquld-solid phase[J].Materiais Protection;2001-11 